\title{
E-Ticketing as a New Way of Buying Tickets: Malaysian Perceptions
}

\author{
Ainin Sulaiman*, Josephine Ng and Suhana Mohezar** \\ Faculty of Business and Accountancy, University of Malaya, 50603 Kuala Lumpur, Malaysia \\ E-mail:*〈ainins@um.edu.my>, **<suhanamohezar@yahoo.com>
}

KEYWORDS e-ticketing; online consumer behavior; e-commerce; online shopping; consumer's perceptions

\begin{abstract}
The main aim of the study is to identify e-ticketing trends among urban communities particularly in Kuala Lumpur. This study investigates the usage trends and patterns of e-ticketing. In addition, the study also focused on the customers' perspectives towards e-ticketing in terms of its usefulness, reliability, security, convenience and efficiency. The study also examines the impact of demographic variables on e-ticketing adoption towards e-ticketing. A survey was carried out among Internet users in Kuala Lumpur. Questionnaires were distributed randomly to 500 people. Kuala Lumpur was chosen as it has the highest number of Internet users. The study found that e-ticketing is not a new phenomenon as nearly fifty percent of the respondents have been buying tickets online for the past two years and purchasing airline tickets seems to dominate the online ticketing services. It was also discovered that convenience and ease of use are among the factors that motivated the respondents to purchase tickets online. The study also revealed that online ticket purchasers are the young, educated and with higher income bracket.
\end{abstract}

\section{INTRODUCTION}

Technological advances has profoundly changed the way consumers buy products and services. Around the globe, the number of Internet users is approximately 655 million in 2002 and is expected to reach 941 million by the end of 2005 (Dholakia and Uusitalo, 2002). Many companies have started using the Internet with the aim of cutting marketing costs, thereby reducing the price of their products and services in order to stay ahead in highly competitive markets. Customers use the Internet not only limited to buy products and services online, but also to compare prices, product features and after sale service facilities they will receive if they purchase the product or services from a particular store.

The rapid growth of Internet users globally provides a bright prospect for e-marketers. According to a study from International Data Corp (IDC), more than 600 million people accessed the Internet globally by the end of 2002 and spent more than US\$1 trillion buying goods and services online (Straits Times, 2002). People are now buying many types of goods and services on the Internet. With the growing numbers and changing trends of buying behavior, an increasing number of companies are also finding it attractive to join the bandwagon and offer the consumers online shopping facilities. A number of studies have tried to examine the profiles and characteristics of online buyers. It is important for marketers to develop a better understanding of the Internet shoppers, as this will help them in developing the effective marketing strategies and tactics in an effort to attract and retain existing customers.

Since the year 2000, many industries have been turning to the Internet to market their product, including the airline industry. The widespread of enthusiasm for e-commerce has lead airline industry to venture into electronic ticketing or e-ticketing. The concept of e-ticketing has entered U.S as far back as in 1980's which is primarily adopted by its domestic carriers; United Airlines in 1984 (www.traveland tourism.com, 2005). In the Asia Pacific region, particularly in the Philippines, Thailand, Hong Kong and Malaysia the e-ticketing service is gaining popularity (SITA, 2005). On the Malaysian front, the concept was first initiated by Air Asia the country's low cost carrier. According to the $11^{\text {th }}$ Malaysia Internet User Survey conducted by AC Nielsen in April 2005, about $14 \%$ of online shoppers bought airline tickets online. Compared to other online shopping transactions, e-ticketing is gaining popularity vastly as the customers can gain costbenefits from buying tickets online. Besides that, other online transactions (e.g. books and apparel) involves uncertainty and risk as the customers are not able to examine the products physically before they decide to buy it. There is limited 
empirical explanation of the drivers behind Malaysia's residents in purchasing airline tickets online. This study is an attempt to investigate the usage trends and patterns of e-ticketing in Malaysia. In addition, the study also focused on the customers' perspectives towards e-ticketing in terms of its usefulness, reliability, security, convenience and efficiency. The study also examines the impact of demographic variables on users' perceptions towards e-ticketing. This paper begins by reviewing the relevant literature pertaining to the area to provide the theoretical background of the study. Thereafter, the methodology is discussed, followed by a description of the findings. The paper concludes with a discussion of the implication of the findings and identifies areas for future research.

\section{E-Ticketing}

Like any other industry, the travel management industry also faces challenges brought by technological advances. E-ticketing by definition combines the issue and delivery of ticket into a single operation (www.traveland tourism.com, 2005). An e-ticketing model allows authorised travel agents to transmit ticketing information directly to the airline's database, enabling passengers to check-in and board the flight without showing a paper ticket. E-tickets substitutes the paper-based flight coupons by an electronic ticket image that is stored in the airline's database. With an e-ticket, details of the passengers' journey are stored in an airline database, and are retrieved" using a unique lookup code. This means that there is no need to issue a physical ticket to the passenger; instead the code can be delivered via the Internet or over the phone.

E-ticketing, the new way of issuing and delivering tickets is becoming prevalent and is employed by many airline companies in an effort to reduce the costs that goes to printing tickets. In India, for instance, it is projected that the e-ticketing will result in 10 to 15 million US dollar saving (www.travelandtourism.com, 2005). While e-ticketing creates cost savings for the airlines companies, travellers get their benefits in terms of convenience. The travellers do not need to carry a paper ticket, which means that the tension of misplacing a ticket is eliminated. Besides, the passengers are allowed to check-in online over the web, see what choice of seats is available on the screen, and make the appropriate choices accordingly. The move towards e-ticketing has also received warm welcome from corporate sectors. The electronic management of ticket information helps the companies in tracking their expenditures and support corporate travel policies more efficiently (Hopkin, 2005)

Globally, in 2005 electronic tickets account for approximately $30 \%$ of all tickets issued, compared to $19 \%$ in 2004 (Gale Group, 2005). A survey of e-ticketing trends (Airline IT Trends Survey, 2004) discovered that $17 \%$ of the major carriers around the world have adopted the e-ticketing model. The pace of e-ticketing adoption is considered remarkable, as it is widely available in most parts of the world for example, Emirates Airlines now offers e-ticketing worldwide, India' Jet Airways has recently adopted it, and Philippine Airline will also do so. According to David (2004), at American Airlines, e-ticketing grew from 55\% in April 2001 to $91 \%$ in 2004. Whereas in the Asia Pacific region, the proportion of e-tickets grew from 10.4 percent to almost 22 percent between January 2004 and March 2005 with a ratio of one to ten of all tickets are sold online (SITA, 2005). Air India entered the e-ticketing market in 2002, when it allowed its customers to buy tickets using credit cards via ICICI Bank's Payment Gateway Service. In Malaysia, e-ticketing is pioneered by Air Asia. The tremendous growth of e-ticketing has actually driven the International Air Transport Association (IATA) to replace the paper tickets with electronic tickets totally by the year 2007 (David, 2004).

In spite of the higher of e-ticketing acceptance rate, not many companies have adopted it. According to the results from 2005 Airline IT Trends Survey conducted by SITA, 29\% of airlines in Europe are still exclusively paper-ticket based, despite the campaign spearheaded by International Air Transport Association (IATA) to shift the industry to hundred percent e-tickets by the end of 2007. The results also revealed that $57 \%$ of airlines in the region cited pricing complexity as a major business issue associated with online ticket sales (SITA group, 2005). On the other hand, in India, the major factor that hinders the companies to adopt e-ticketing is due to the negative perceptions of the consumers (www.expresstravelandtourism.com, 2005). Kolsaker et al. (2004) who focused their studies in Hong Kong observed that although 
consumers acknowledge the convenience offered by the web, they also recognized simultaneously the risks associated with buying tickets online. The study indicated that fear of financial loss through credit card fraud ranks as the critical factor in purchasing airline tickets via Internet. In addition, some airline companies claimed that "not enough buyers" was the biggest issue that hinders the implementation of e-ticketing (www.travelandtourism.com 2005).

The development of e-ticketing is also hampered by inadequate infrastructure. According to Tan (2005), airline companies in Africa, for instance find it hard to catch up with technological advancement in the airline industry due to the less developed infrastructure. Meanwhile, in North America and Europe, where the technologies are widely available, Tan (2005) reported that because of financial difficulty, some airline companies in the regions failed to keep up with the e-ticketing model. Airlines IT Survey 2005 , indicated that $20 \%$ of airlines in Europe and North America will not have the majority of their systems IP-enabled due to their financial constraint (IP is the underlying communication technology that enables many new applications such as web-based booking systems) (SITA, 2005).

\section{Online Purchasing Behavior and Socio-Demographic Factors}

Various studies have tried to gain an improved insight into understanding the consumer behavior in cyberspace (Butler and Peppard, 1998; Chen and Shergill, 2005; Kolsaker et al., 2004). According to Shwu (2003) and Burke (2002), consumer purchases decision are influenced strongly by demographic, economic, social, situational and technological factors. Four relevant demographic factors; age, gender, education and income are found to be significant with the consumers' attitude towards online shopping. Schiffman and Kanuk (1997) suggested that the higher the consumers' socio-economic status, (measured by education, income, and occupational status) the more positive the consumers' perceptions of online buying relative to offline buying.

In addition Wood (2002) in his studies found that younger adults, those under 25 years old are more interested in using technologies like the Internet to find out about new products, search for product information and compare and evaluate alternatives. Ratchford et al. (2001) on the other hand suggested that the reason for this is that older consumers may perceive the benefits of Internet shopping to be less than the cost of investing in the skill needed to do it effectively, and therefore avoid shopping on the Internet. Earlier studies done by Steenkamp et al. (1999) and Venkataram and Price (1990) indicated that consumers' innovativeness is lower among older consumers, and they tend to be satisfied with conventional shopping methods.

Besides age, gender is also found to be an important variable in determining the consumers' attitudes towards online shopping. Monsuwe et al. (2004) reported that males express a greater favorable attitude towards internet shopping than females. They are more positive about using the Internet as a shopping medium, whereas female shoppers prefer to use catalogs to shop at home. Similarly Shwu (2003) discovered that the mean attitude score for males towards online shopping was significantly higher than for females. Nevertheless, Wallace (2005) noted that the increasing use of the Internet by women, their growing economic power and their dominant influence on household shopping behaviors have made them a market segment to be targeted in the future.

According to Burke (2002) and Dholakia and Uusitalo (2002) education is found to affect the adoption behavior of online purchasing. Li et al. (1999) suggested that the reason for this is that education is often positively correlated with an individual's level of Internet literacy. Higher educated consumers are found to be more comfortable in using non-store channels, such as Internet to shop.

Income is one of the demographic factors that are often included in previous studies. Monsuwe et al. (2004) reported that consumers with higher household incomes tend to shop more online compared to lower income consumers. This finding is found to be consistent with the previous studies done by Danthu and Gracia (1999) and Hoffman et al. (1999). Consumers with middle-income groups are most likely to shop using Internet as a medium. The explanation of these findings could be that higher household incomes are often positively correlated with possession of computers, Internet access and higher education levels of consumers (Lohse et al., 2000). 
Online Purchasing Behavior and Consumers' Perceptions

Consumers decisions whether to shop or not to shop online are also influenced by the consumers perceptions towards online shopping. Previous studies have found those online shopping effect consumers' perceptions in terms of its usefulness (Davis,1993; Venkatesh, 2000), perceived risk and trust(Kini and Chobiah, 1998; Wee and Ramachandra, 2000) and convenience (Childers et al., 2001; Kare-Silver, 2001).

According to Davis $(1989,1993)$, "usefulness" is defined as the individual's perception that using the new technology will enhance or improve her or his performance. Usefulness in the context of online shopping refers to consumers' perceptions that using the Internet as a shopping medium enhances the outcome of their shopping experiences (Monsuwe et al., 2004). Apart from this, Venkatesh (2000) and Dalbhokar (1996) linked the usefulness with "ease of use" to determine consumers' attitude towards online shopping. According to them, usefulness is influenced by ease of use because the easier a technology is to use, the more useful it can be. Jeong and Lambert (1999) showed that customers' attitudes towards the usability of website together with their perceptions of the usefulness and quality of the website information were the best indicators of consumers' purchasing behaviour.

Kare-Silver (2001) discovered that convenience is at the heart of what fundamentally drives demand for the Internet. Similarly, Wolfbinger and Gilly (2001) found that the most important attributes of online shopping to consumers are convenience and accessibility. The consumers have a greater intention to shop online because it saves time and effort. In addition, by using the Internet to shop, they can shop in the comfort of their home environment. Avery (1996) pointed that consumers who are not able to shop in traditional stores owing to an illness or other immobilizing factors, tend to turn to the Internet as another alternative for shopping.

While flexibility, convenience, efficiency, and enjoyment are some examples of positive feelings customers may have about shopping online, the concerns about the possible risks of online transactions and lack of control are hard to ignore. Wee and Ramachandra (2000) found that surfers who did not purchase online expressed concerns about security, privacy and trustworthiness. Similarly, Lee and Turban (2001) in their study discovered that lack of trust is one of the most frequently cited reasons for consumers not to shop online. The difficulties of physically checking the quality of products or monitoring the safety and security of sending sensitive personal and financial information while shopping on the Internet adds to the perceived risk. Monsuwe et al. (2004) pointed that violation of consumers' trust in online shopping, in terms of privacy invasion or misuse of personal information negatively influenced attitude towards online shopping and leads to the reluctant behaviour among consumers to shop on the Internet in future.

\section{RESEARCH METHOD}

A questionnaire was used to enquire about the respondents' perception on the usage of e-ticketing. The questionnaire was divided into 3 sections. Section A focused on collecting the respondents' demographic details, such as gender, age, and personal income. Section B was used to determine the respondents' perception on e-ticketing, such as its usability, compatibility, and security while Section C was used to collect data on the trends of e-ticketing usage. A 7-point Likert scale was used for all items ranging from "strongly agree" to "strongly disagree". Respondents indicated their level of agreement with carefully constructed statements that ranged from positive to very negative toward the attitudinal object. A convenience sampling method was used to obtain respondents, as this method is convenient and economical. The targeted respondents were working adults, age between 18 to 55 years old, and are Internet users. In an attempt to examine the effect of demographic variables, this study has divided the targeted respondents into different group based on gender, ethnicity, marital status, age, education level, and profession. In terms of age, the targeted respondents were divided into four different groups; "18 to 25 ", "26 to 35", "36 to 45 " and "above 40 " years old. Similarly, they were also divided into five different groups of professions; "professionals", "top level management", "middle level management", "operational level" and others. Other would include respondents who are students or self-employed. Besides that, the targeted respondents were also be divided into three different groups of education level; 
"non-degree holder", "bachelor degree holder", "postgraduate degree holder". In order to examine the effect of ethnicity on e-ticketing adoption, the targeted respondents were divided into four different groups of ethnicity; "Malays", "Chinese", "Indians", and others. Malays, Chinese and Indians are three largest group of ethnicity in Malaysia. A self-administered questionnaire was distributed to 500 people randomly in selected areas of Kuala Lumpur, the capital city of Malaysia. Kuala Lumpur was chosen as it has the highest Internet users' population (Eight Malaysia Plan, 2001-2005). Despite distributing the questionnaire personally to the respondents, not all of them returned the questionnaire. In order to increase the response rate, the researchers assisted them to fill in the questionnaire. Finally, only 291 questionnaires were returned back.

\section{RESULTS AND FINDINGS}

The sample group of this study consists of 291 respondents $(58 \%)$ response rate. It was found that $56.4 \%$ of the respondents used e-ticketing, while $43.6 \%$ of them did not use e-ticketing. In terms of gender, it is found that $52.6 \%$ of the respondents are female, while the remainders are males. Over half of the respondents $(56.7 \%)$ are between $26-35$ years old. Majority of the respondents are married with children (47.4\%). In terms of ethnicity, the Chinese $(65.3 \%)$ dominate the respondents group. The respondents mainly are professionals $(27.5 \%)$ and hold managerial position (30.6\%). Approximately $60 \%$ of the sampled respondents possess a bachelor's degree qualification. This profile actually reflects the profile of the Malaysian Internet users.

\section{Relationship Between Demographic Variables and E-Ticketing Adoption}

Chi-square analysis was performed to test the relationship between demographic variables (age, income level, education level, gender, ethnicity, and marital status) and e-ticketing adoption (Table 1). It was found that only age, level of education and profession have impact on e-ticketing adoption. Age was found to be significant at 0.009 . E-ticketing is found to be more popular among consumers, age between 26 to 35 years old. The results were found to be contradicting with previous study (Kraut et al., 1996), which found that Internet users are more popular among 18 to 26 years old. The reason behind this phenomenon could be due to the fact that 26-35 years old age groups maybe the group that is employed and possess credit card. In addition, the fact that this segment of consumers has busy lifestyles and are constrained by time may also contribute to the phenomenon. This study also discovered that consumer's profession has a significant effect on e-ticketing adoption $(\mathrm{p}=0.005)$. E-ticketing adoption is found to be more prevalent among consumers who are professionals or hold managerial positions. The reasons behind this could be because these groups of consumers are more familiar with the Internet and computer usage compared to other groups. It could also be observed from Table I that level of education has an effect on e-ticketing adoption. This is expected as previous study shows that education level is positively correlated with an individual's Internet literacy (Li et al., 1999)

Table 1: Demographic variables and e-ticketing adoption

\begin{tabular}{lll}
\hline Variables & Asym.sig & $\begin{array}{l}\text { Significant/Not } \\
\text { Significant }\end{array}$ \\
\hline Age & 0.009 & Significant \\
Gender & 0.7 & Not significant \\
Level of Education & 0.005 & Significant \\
Income & 0.9 & Not significant \\
Profession & 0.007 & Significant \\
Ethnicity & 0.12 & Not significant \\
Marital Status & 0.58 & Not significant \\
\hline
\end{tabular}

\section{E-ticketing Trends}

Table 2 depicts the usage pattern of e-ticketing among Malaysian consumers. It can be observed that the majority of the respondents only use e-ticketing when necessary $(83.5 \%)$ with nearly $35 \%$ of them claiming that they have been using it for the last two years. The results also indicate that most of the users used e-ticketing services to buy airline tickets $(83.5 \%)$ with approximately $60 \%$ of the users visiting AirAsia website, and $22.6 \%$ visiting Malaysia Airline Bhd. This could be attributed to the cost-savings benefits provided by e-ticketing service in airline industry. Moreover, Air Asia provides low travel cost. The e-ticketing module for other industry such as entertainment and sports are still at an infancy stage, and it is not widely used by the consumers. 
Table 2: Usage trends

\begin{tabular}{|c|c|c|c|}
\hline Items & Categories & Freq. & $\%$ \\
\hline Frequency of & Less than once a month & 12 & 7.3 \\
\hline \multirow[t]{4}{*}{ Usage } & About once a month & 9 & 5.5 \\
\hline & A few times a month & 5 & 3.0 \\
\hline & About once a day & 1 & 0.6 \\
\hline & When necessary & 137 & 83.5 \\
\hline \multirow[t]{5}{*}{$\begin{array}{l}\text { Period of } \\
\text { E-Ticketing Usage }\end{array}$} & $\begin{array}{l}\text { One month to } \\
<\text { six month }\end{array}$ & 4 & 2.4 \\
\hline & 6 months to $<$ a year & 21 & 12.8 \\
\hline & $\begin{array}{l}1 \text { year to less than } \\
2 \text { years }\end{array}$ & 57 & 34.8 \\
\hline & $\begin{array}{l}2 \text { years to less than } \\
3 \text { years }\end{array}$ & 40 & 24.4 \\
\hline & 3 years and above & 42 & 25.6 \\
\hline Events Used for & Travel by air & 137 & 83.5 \\
\hline \multirow[t]{4}{*}{ E-Ticketing } & Travel by land & 2 & 1.2 \\
\hline & Cinema & 19 & 11.6 \\
\hline & Sport event & 1 & 0.6 \\
\hline & Concerts & 5 & 3.0 \\
\hline Websites & Malaysia Airline Berhad & 37 & 22.6 \\
\hline \multirow[t]{8}{*}{ Patronized } & AirAsia & 97 & 59.1 \\
\hline & Singapore Airlines & 1 & 0.6 \\
\hline & Keretapi Tanah Melayu & 1 & 0.6 \\
\hline & Plusliner & 1 & 0.6 \\
\hline & Golden Screen Cinemas & 17 & 10.4 \\
\hline & Axcess.com & 3 & 1.8 \\
\hline & Genting.com & 3 & 1.8 \\
\hline & Others & 4 & 2.4 \\
\hline Place Conduct & Home & 95 & 57.9 \\
\hline \multirow[t]{2}{*}{ E-Ticketing } & Office & 61 & 37.2 \\
\hline & Internet Café & 8 & 4.9 \\
\hline & Family & 27 & 16.5 \\
\hline \multirow[t]{3}{*}{ Influence } & Friends & 88 & 53.6 \\
\hline & Advertisement & 36 & 22.0 \\
\hline & Others & 13 & 7.9 \\
\hline
\end{tabular}

Users mainly conduct e-ticketing activities from home $(57.9 \%)$ and office $(37.2 \%)$. It is found that the percentage of the users who conducted the activities from Internet café is small (4.9\%) and none of them conducted from school or public library. This is expected, as majority of e-ticketing users are working adults. The results also illustrated that majority of the users $(56.3 \%)$ are influenced by friends to purchase tickets via the Internet.

\section{Motivating Factors and Barriers towards E-Ticketing}

Convenience $(\mathrm{M}=5.90)$ and ease of use $(M=6.05)$ were cited as the top two positive perceptions of the users towards e-ticketing (Table 3). In terms of ease of use, the majority of respondents agreed that purchasing tickets online is easy to conduct and effortless. This could be explained by the fact that most of the e-ticketing users in the sample are highly educated which reduced the complexity of conducting transactions online. Besides easy to use, the users also agreed that by using the Internet to buy tickets, they can eliminate the tendency of misplacing or losing tickets. In addition, the users also perceived the e-ticketing service as a convenient way to buy tickets. Factors such as inconvenience in queuing up at the counter to buy tickets may lead the users to use e-ticketing service.

Table 3: Users' perception towards e-ticketing

\begin{tabular}{llll}
\hline S. & Item & $\begin{array}{l}\text { Mean } \\
\text { Scores }\end{array}$ & S.D. \\
\hline 1 & Easy & 6.05 & 1.158 \\
2 & Convenient way & 5.90 & 1.059 \\
3 & Cost saving & 5.66 & 1.167 \\
4 & Low Cost of Cancellation & 5.57 & 1.316 \\
5 & Elimination of ticket loss & 5.51 & 1.386 \\
6 & Useful for planning & 5.31 & 1.289 \\
7 & Compatible with lifestyle & 5.12 & 1.230 \\
8 & Confident on security & 5.05 & 1.655 \\
9 & Fits well with personal taste & 4.89 & 1.172 \\
10 & Fits well with working style & 4.85 & 1.127 \\
11 & No privacy & 4.85 & 1.443 \\
12 & Enlightening & 3.82 & 1.572 \\
13 & Lots of mental effort & 2.48 & 1.476 \\
\hline
\end{tabular}

In order to determine barriers of e-ticketing, those respondents who did not buy ticket online are asked to indicate reasons for not doing so (Table 4). It can be observed that the biggest concern that hinders the consumers to buy tickets online is that they do not have confidence or trust the system (item 1-49.6\%). This finding is consistent with the earlier study by Monsuwe et al. (2004).

Table 4: Reasons for not using e-ticketing

\begin{tabular}{llrr}
\hline S. No. Item & Frequency & \multicolumn{1}{c}{$\%$} \\
\hline 1 & No confident/trust & 63 & 49.6 \\
2 & Do not have computers & 7 & 5.5 \\
3 & Do not know how to use & 8 & 6.3 \\
4 & Do not have internet access & 10 & 7.9 \\
5 & Transaction not secure & 15 & 11.8 \\
6 & Not aware of service & 10 & 7.9 \\
7 & Others & 14 & 11.0 \\
\hline & Total & 127 & 100.0 \\
\hline
\end{tabular}

\section{Differences between e-Ticketing Adopters and Non e-Ticketing Adopters}

This section highlights the differences between the e-ticketing adopters and non e-ticketing adopters in terms of Internet 
knowledge and website evaluation. Figure 1 illustrates the frequency of Internet usage among e-ticketing adopters and non adopters. It could be observed from the graph that most e-ticketing adopters perform Internet activities daily, compared to non e-ticketing users who mainly perform Internet activities when it is necessary to do so. Chi-square analysis was further performed to determine the relationship between frequency of Internet usage and e-ticketing adoption. The result is found to be significant at $\mathrm{p}=0.000$.

This study also tries to determine the purpose of Internet usage among the respondents. It is discovered that both e-ticketing adopters and non e-ticketing adopters used Internet mainly to gather information and for communication purposes (Table 5). It is also found that e-ticketing adopters used Internet as a medium for e-shopping more than non e-ticketing adopters. Further analysis using t-test was performed to examine whether the mean for Internet knowledge is same between e-ticketing adopters and non e-ticketing adopters. The results indicated that there is a statistically significant difference between the mean of Internet knowledge for e-ticketing adopters and non e-ticketing adopters at $\mathrm{t}=3.124$ and $\mathrm{p}=0.000$. Thus, this result implied that in terms of Internet knowledge, e-ticketing adopters are found to have a sound knowledge of Internet usage compared to non e-ticketing adopters.

Table 5: Internet knowledge

\begin{tabular}{lcc}
\hline & \multicolumn{2}{c}{ Mean Scores } \\
& Adopters & Non-Adopters \\
\hline $\begin{array}{l}\text { I am very skilled at using } \\
\text { the Internet }\end{array}$ & 4.72 & 4.10 \\
I consider myself knowle- & 4.82 & 4.12 \\
dgeable about search techniques. & \\
I have some control over & 4.38 & 3.86 \\
the content of the website \\
$\quad$ that I want to see
\end{tabular}

\section{CONCLUSION}

The aim of the research was to study the perceptions of Internet users in Malaysia towards e-ticketing. We began by examining the usage patterns of e-ticketing. It could be concluded that e-ticketing services are not new to the consumers in Malaysia, as more than half of the respondents have been purchasing tickets online for the last 2 years ago. As expected, high percentage of e-ticketing users purchased airline tickets compared to other types of tickets (entertainment, sports and etc). This is perhaps due to the effective sales and promotions done by the airline company in its effort to create awareness among the consumers. In addition, the price offered by Air Asia is considerably cheaper than the other airlines.

Our findings on motivators and barriers of e-ticketing clearly indicate that convenience and ease of use serve as strong factors that motivate consumers to purchase tickets online. Security and privacy concern was found to be the biggest barriers of e-ticketing. Lastly, we deduced findings from this study that age, level of education, and professions have significant impact on the users' perceptions towards e-ticketing. A user of e-ticketing belonged most to age group of 26 to 35 years old. Consumers, who hold the managerial position, and possess high level of education is more positive towards adopting e-ticketing services.

Results from this study could serve as a basis for the e-ticketing service providers in identifying the typical users of e-ticketing service based on their demographics, and thus point out the right market segment to target. This knowledge affects a range of decisions, such as determining the type of advertising campaign.

In addition, e-ticketing service providers can also use the findings to improve the way information about the e-ticketing service is disseminated.

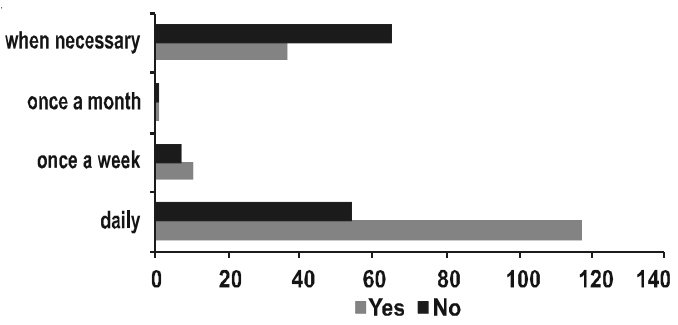

Fig. 1. Frequency of internet usage 
Disseminating information through the right mode of communication for different consumer segments is likely to increase each segment's probability of adopting e-ticketing services.

This study however has its limitation. Majority of the respondents were highly-educated and have high income status. These characteristics create a bias and constrain our ability to extrapolate from the findings. Nevertheless, the study serves as a point for more in-depth analysis and discussion on e-ticketing behaviour in Malaysia.

\section{REFERENCES}

Anonymous. 2002. "Global Internet users to hit $600 \mathrm{~m}$ this year." Strait Times, February 14, 2002 p.14.

Avery, P. J. 1996. "Determinants of search for nondurable goods:an empirical assessment of the economics of information theory." The Journal of Consumer Affairs, 30(2): 390-406.

Burke, R.R. 2002. "Technology and the customer interface: what consumer want in the physical and virtual store." Journal of the Academy of Marketing Science, 30(4): 411-432.

Butler, P. and J. Peppard. 1998. "Consumer purchasing on the Internet: processes and prospects." European Management Journal, 16(5): 600-610.

Chen, Z. and G. Shergill. 2005. "Web-based shopping: consumer's attitudes towards online shopping." Journal of Electronic Commerce Research, 6(2): 79-94.

Childers, T. L., C. L. Carr, J. Peck and S. Carson. 2001. "Hedonic and utilitarian motivation for online retail shopping behaviour." Journal of Retailing, 77(4): 511-535.

Dalbhokar, P., A. 1996. "Consumer evaluations of new technology-based self-service option". International Journal of Research in Marketing, 13(1): 29-51.

Danthu, N. and A. Garcia. 1999. "The Internet Shopper." Journal of Advertising Research, 22(1): 22-30.

David, D. 1989. "Perceived usefulness, perceived ease of use, and user acceptance of international technology." MIS Quarterly, 13(3): 319-340.

David, F. 2004. "A Paperless World." Airline Business, 20(7): 58-59.

Davis, D. 1993. "User acceptance of information technology: system characteristics, user perceptions and behavioural impacts." International Journal of Man-Machine Studies, 38(3): 475-487.

Dholakia, R.R. and Uusitalo. 2002. "Switching to Electronic Stores: Consumer Characteristics and the Perception of Shopping Benefits." International Journal of Retail and Distribution Management, 30(10): 459-469.

Hoffman, P. L., T. P. Novak and M. Peralta. 1999. "Building consumer trust online." Communications of the ACM, 42(4): 80-85.

Home Page of Gale Group. Retrieved February 18, 2006, from http://www.gale.com/research-articles/A034archive.htm

Home Page of Internet News for Internet Business. Retrieved September 9, 2005, from www.thestandard .com/article/display/0, 1151, 16632, 00.html
Home Page of Network World. Retrieved March 1, 2006, from www.networkworld.com/news/2003/ 0929airline.html

Home Page of Travel and Tourism. Retrieved September 14, 2005, from http://www.travelandtourism.com/ 20030731/cover.shtml

Home Page of ZDNet Asia. Retrieved January 9, 2006, from http://www.zdnetasia.com/news/business/0, 39044229, 39252756, 00.htm

Hopkins, R. 2005. "Travel Management Faces New Tests." Euromoney, 26(43):188-193.

Jeong, M. and C. Lambert. 1999. "Measuring information quality on lodging websites." Journal of Hospitality Information Technology, 23(2): 87-99.

Kare-Silver. 2001. E-shock: the new rules. New York: Palgrave.

Kini, A. and J. Chobiah. 1998. "Trust in electronic commerce: definition and theoretical consideration." Paper presented in $31^{\text {st }}$ Hawaii International Conference on System Science in Hawaii, USA, January 1998.

Kolsaker. A., L. L. Kelley and P. C. Choy. 2004. "The Reluctant Hong Kong Consumer: Purchasing Travel Online." International Journal of Consumer Studies, 28(3): 295-304.

Kraut, R., W. Scherlis, T. Mukhopadhyay, J. Manning and S. Kiesler. 1996. "The Home Net field trial of residential internet services." Association for Computing Machinery, Communications of the ACM, 39(12): 55-53.

Lee, M., K., O. and E. Turban. 2001. "A trust model for consumer Internet shopping." International Journal of Electronic Commerce, 6(1): 75-91.

Li., H., C. Kuo and M. G. Russell. 1999. "The impact of perceived channel utilities, shopping orientations, and demographics on the consumers' online buying behaviour." Journal of Computer-Mediated Communication, 5(2): 2-25.

Lohse, G.L. and P. Spiller. 2000. "Internet retail store design: how the user interface influences traffic and sales." Journal of Computer Mediated Communication, 5(2): 219-234.

Monsuwe, T.P, B. G. C. Dellaert and K. D. Ruyter. 2004. "What drives consumer to shop online? A literature review." International Journal of Service Industry Management, 15(1): 102-121.

Ratchford, B.T., D. Talukdar and M. S. Lee. 2001. "A model of consumer choice of the Internet as an information source." International Journal of Electronic Commerce, 5(3): 7-21.

Schiffman, L.G. and L. L. Kanuk. 1997. Consumer Behaviour. Englewood Cliffs, N.J.: Prentice Hall.

Shwu, W. 2003. "The relationship between consumer characteristics and attitude toward online shopping." Marketing Intelligence and Planning, 21(1): 37-44.

Steenkamp, J.B.E.M, F. Hofstede and M. Wedel. 1999. "A cross-national investigation into the individual and national cultural antecedents of consumer innovativeness." Journal of Marketing, 63(1): 5569.

Venkataram, M.P. and L. L. Price. 1990. "Differentiating between cognitive and sensory innovativeness: concepts, measurement, and implications." Journal of Business Research, 20(1): 293-315.

Venkatesh, V. 2000. "Determinants of perceived ease 
of use: integrating control, intrinsic, motivation, and emotion into the technology acceptance model." Information System Research, 4(4): 342-365.

Wee, K. N. L. and R. Ramachandra. 2000. "Cyberbuying in China, Hong Kong, and Singapore: Tracking the who, where, why and what of online buying." International Journal of Retail and Distribution
Management, 28(7): 307-316.

Wolfbinger, M. and M. C. Gilly. 2001. "Shopping online for freedom, control, and fun." California Management Review, 43(2): 34-55.

Wood, S. L. 2002. "Future fantasies: a social change perspective of retailing in the $21^{\text {st }}$ century." Journal of Retailing, 78(1): 77 